\title{
Cerebrovascular Responses in the Fetal Sheep Brain to Low-Dose Endotoxin
}

\author{
EDWIN YAN, MARGIE CASTILLO-MELÉNDEZ, TRISHA NICHOLLS, JONATHAN HIRST, AND \\ DAVID WALKER
}

Department of Physiology, Monash University, Clayton, Victoria, 3800, Australia

\begin{abstract}
ABS
Clinical and experimental evidence indicate that infection in
pregnancy is associated with fetal brain damage. However, the
inflammatory processes that compromise the fetal brain are not
fully understood. In this study, we used a single, low dose of
lipopolysaccharide (LPS, $0.1 \mu \mathrm{g} / \mathrm{kg}$ i.v.) to provoke an acute-
phase response in unanesthetized fetal sheep in utero. COX-2
mRNA was increased in the cortex and cerebellum at 24 and $48 \mathrm{~h}$
after LPS, and immunoreactive COX-2 protein was increased in
perivascular cells throughout gray and white matter at $24 \mathrm{~h}$ after
LPS administration. Plasma albumin was observed in the paren-
chyma of the brain in cortex, thalamus, hypothalamus, corpus
callosum, fornix, hippocampus, midbrain, subcallosal bundle,
and cerebellar Purkinje cells. Large, rounded, lectin-positive
cells with the appearance of macrophages were observed around
blood vessels in subventricular white matter. These results indi-
cate that blood-brain barrier permeability is increased in the fetal
brain after exposure to endotoxin and suggests that cytotoxic and
\end{abstract}
There is a strong association between perinatal brain damage and intrauterine infection in human pregnancy (1). Infection is associated with histologic evidence of vascular inflammation of the umbilical cord (2), raised cytokine levels in amniotic fluid $(3,4)$, and increased incidence of white matter damage in the brain of the neonate (5). Nonetheless, the inflammatory responses provoked by infection in the fetus, and the events that lead to compromise of the fetal and neonatal brain, are poorly understood.

Stimulation of the immune system by the bacterial endotoxin LPS leads to a series of host responses known as the acutephase reaction. The acute-phase reaction is mediated in large part by inflammatory cytokines (6). Cytokines in the circulation cross the BBB slowly and in amounts too small to stimulate inflammatory responses in the brain itself (7). However, cytokine receptors present on the luminal surface of the

Received October 9, 2002; accepted December 8, 2003

Correspondence: David Walker, Ph.D., Department of Physiology, Monash University, Clayton, Victoria, 3800, Australia; e-mail: david.walker@med.monash.edu.au

Supported by a Monash University Postgraduate Scholarship (E.Y., T.N.) and a National Health and Medical Research Council of Australia grant (D.W., J.H., M.C.M.).

DOI: 10.1203/01.PDR.0000115681.95957.D4 pro-inflammatory substances could pass from the circulation into the brain after peripheral inflammatory stimulation. (Pediatr Res 55: 855-863, 2004)
BBB, blood-brain barrier
Abbreviations
COX-1, cyclooxygenase type-1
COX-2, cyclooxygenase type-2
GAPDH, glyceraldehyde 3-phophate dehydrogenase
iNOS, inducible nitric oxide synthase
LPS, lipopolysaccharide
NO, nitric oxide
PB, phosphate buffer
PG, prostaglandin
RNase, ribonuclease
TNF- $\alpha$, tumor necrosis factor- $\alpha$

endothelial cells of cerebral blood vessels (8) may lead to stimulation of PG production on the basal side of the endothelial cell (9). This suggests that endothelial-derived PG could act on signal transduction pathways within the CNS, leading to the febrile response (10), changes of the sleep-wake cycle, and activation of the autonomic nervous system and hypothalamopituitary-adrenal axis (11).

COX-1 and COX-2 are the rate-limiting enzymes for PG production from arachidonic acid. COX-1 is constitutively expressed in many cell types and is relatively unaffected by immune stimulation (12). In the adult brain, the constitutive synthesis of PG may be important for maintaining neuronal metabolism and synaptic function. COX-1 is localized to specific regions in fetal sheep brain, including some regions of cortex, hypothalamus, hippocampus, midbrain, pons, and medulla (13). In contrast to the COX-1 isoform, COX-2 expression is usually minimal under basal conditions but is induced by inflammatory stimuli such as LPS or IL-1 $(10,14-18)$. In the adult rat brain, induction of COX-2 mRNA in response to systemic LPS injection occurred first in large blood vessels, and then in small vessels of the cerebral cortex and hippocampus $(6,15,19,20)$, effects that were resolved approximately $8 \mathrm{~h}$ 
after LPS administration. COX-2 inhibition studies suggest that $\mathrm{PG}$ production is responsible for the increase of $\mathrm{BBB}$ permeability (21). Pretreatment with dexamethasone, which also suppresses the induction of COX-2, reduced penetration of a high molecular weight tracer in LPS-treated adult mice brain in a dose-dependent manner (22). These findings suggest that PG production via COX-2 has a role in the increase of $\mathrm{BBB}$ permeability that often occurs during systemic and CNS inflammatory conditions in the adult. Expression of COX-2 under inflammatory conditions or after infection has not been fully investigated.

The BBB is impermeable to large molecules such as proteins from early gestation in sheep $(23,24)$. Permeability to smaller molecules such as $\alpha$-aminoisobutyric acid decreases between 0.6 and 0.9 of gestation (term $=147$ days) in the sheep fetus, a change associated with the increase of cortisol secretion (25). Although the effects of infection and inflammation on the BBB of adult animals have been studied extensively (26), little is known of the effects of infection in utero on the fetal BBB. Clinically, it is not clear how much and by which route endotoxins enter the fetal circulation, but it is likely that the fetus is usually exposed to quite small amounts of endotoxin. In fetal sheep, doses of LPS $>1 \mu \mathrm{g} / \mathrm{kg}$ can be fatal (27), whereas doses of $1-100 \mu \mathrm{g} / \mathrm{kg}$ are often used in studies of the adult laboratory animal $(16,28)$. In this study, using a low dose of LPS $(0.1 \mu \mathrm{g} / \mathrm{kg})$ that produced only transient effects on fetal $\mathrm{pH}$ and blood gas parameters, we found that LPS caused changes of cerebral COX-2 expression and penetration of endogenous albumin and peripheral macrophages into the brain. These results indicate that the fetal brain could be vulnerable to damage caused by entry of cytotoxic substances from the circulation.

\section{METHODS}

\section{Animals and Experimental Protocol}

Twenty-two Merino/Border-Leicester cross pregnant sheep of known gestational age were used for this study. The ewes were housed in individual cages with free access to water, and their environment kept constant at a room temperature of $22^{\circ} \mathrm{C}$ and a 12-h light/dark cycle. All the experimental procedures had received prior approval from the Standing Committee on Ethics and Animal Experimentation of Monash University. Surgery was performed at $125 \pm 1 \mathrm{~d}$ of gestation under halothane (Fluothane; ICI, Melbourne, Victoria, Australia) anesthesia for implantation of fetal carotid artery and jugular vein catheters as previously described (29). Each catheter was flushed with heparinized saline daily to prevent clotting.

After a postsurgical recovery period of 7-8 d, the effect of systemic administration of the bacterial endotoxin LPS (Sigma Chemical, St. Louis, MO, U.S.A.) on cerebrovascular COX-2 expression and albumin extravasation was determined in 11 fetuses at $133 \pm 1 \mathrm{~d}$ of gestation. Each fetus received $0.1 \mu \mathrm{g} / \mathrm{kg}$ LPS, for an estimated body weight for the gestational age. Another 11 age-matched fetuses were treated with an equal volume $(1 \mathrm{~mL})$ of saline. The LPS or saline was injected slowly over 2-3 min. Fetal blood gas parameters and $\mathrm{pH}$ were measured from a $0.2-\mathrm{mL}$ arterial blood sample taken at -1.5 ,
$-1.0,-0.5,0.5,1.0,1.5,2,3,4,6,8,12,22,24$, and $48 \mathrm{~h}$ with respect to the time of administration of LPS or saline. Three LPS-treated and three saline-treated ewes were killed $24 \mathrm{~h}$ after treatment by i.v. injection of pentobarbitone sodium (Lethabarb, Virbac Pty. Ltd., Peakhurst, NSW, Australia) to the ewe, and the fetal brain was quickly removed, and blocks comprising pieces of the cerebral cortex and the cerebellum were immediately frozen in liquid $\mathrm{N}_{2}$ and stored at $-70^{\circ} \mathrm{C}$ until analysis of COX-2 mRNA. The brains of another three LPS- and three saline-treated fetuses were collected in the same fashion at $48 \mathrm{~h}$ after treatment and also kept frozen for COX-2 mRNA assay. The brains of the remaining five LPSand five saline-treated fetuses were collected $24 \mathrm{~h}$ after treatment by perfusion via the left ventricle with heparinized saline, followed by approximately $1 \mathrm{~L}$ of $4 \%$ paraformaldehyde (ProSci Tech, Thuringowa, QLD, Australia) in $0.1 \mathrm{M} \mathrm{PB}$ at pH 7.4. The brains were then removed from the skull and postfixed by immersion in $4 \%$ paraformaldehyde for $4 \mathrm{~h}$, and then placed in $20 \%$ (wt/vol) sucrose in $4 \%$ paraformaldehyde overnight. Each brain was dissected into small blocks according to the anatomical regions (cerebral cortex, thalamus and hypothalamus, midbrain, cerebellum) and stored in 30\% (wt/vol) sucrose in $0.1 \mathrm{M} \mathrm{PB}$ until sinking to the bottom of the container; they were then stored at $-70^{\circ} \mathrm{C}$.

\section{COX-2 mRNA}

Total RNA in samples $(\sim 1.5 \mathrm{~g})$ of cerebral cortex and cerebellum was extracted by homogenization in a guanidine thiocyanate/phenol solution (Tri-reagent, Sigma Chemical Co.). RNA concentration was determined by absorbance at 260 $\mathrm{nm}$ and RNA integrity was assessed using agarose gel electrophoresis. The COX-2 cRNA probe was transcribed from an ovine cDNA (ORF 98-491) (30). The level of GAPDH mRNA was assayed together with COX-2 mRNA by a RNase protection assay using a RPA II kit (Ambion, Austin, TX, U.S.A.) to confirm that equal amounts of total RNA were used for each sample. The assay was conducted according to manufacturer's protocol. Briefly, the ${ }^{32} \mathrm{P}$-labeled anti-sense COX-2 and GAPDH probes were hybridized at $42^{\circ} \mathrm{C}$ overnight with 60 $\mu \mathrm{g}$ total RNA. After the hybridization reaction, unhybridized single-stranded probe was digested by RNase treatment, and the remaining protected probe was run on a denaturing sequencing gel to separate hybridized fragments according to size. A Phosphor Imager screen (Molecular Dynamics, Sunnyvale, CA, U.S.A.) was used to detect the radioactive signal, which was then scanned by a Phosphor Imager scanner (STORM 860, Molecular Dynamics). The intensity of each protected RNA band, representing COX-2 and GAPDH mRNA expression, was quantitated by the ImageQuaNT program (Molecular Dynamics). COX-2 mRNA expression is presented as the densitometric ratio of the COX-2 and GAPDH mRNA levels.

\section{Immunohistochemistry}

Albumin. The paraformaldehyde-fixed brain sample was cut into $40 \mu \mathrm{m}$ thick sections at $-18^{\circ} \mathrm{C}$ using a cryostat (CM1800, Leica, Nussloch, Germany). The detection of albumin in the 
brain parenchyma was performed by free-floating immunohistochemistry. Nonspecific binding was first blocked by incubating the section in $5 \%$ soya milk in PBS $(0.1 \mathrm{M}, \mathrm{pH} 7.4)$ for 45 $\mathrm{min}$ at room temperature. Sections were then incubated with rabbit anti-sheep albumin antibody (1:6000 dilution, Accurate Chemical \& Scientific, Westbury, NY, U.S.A.) at $37^{\circ} \mathrm{C}$ for $1 \mathrm{~h}$ in the presence of $2 \%$ soya milk and $0.3 \%$ Triton X-100 in PBS. After washing in PBS, the section was incubated with a goat anti-rabbit secondary antibody (1:200 dilution, Vector Laboratories, Burlingame, CA, U.S.A.) for $1 \mathrm{~h}$ at room temperature, followed by a 30-min incubation with streptavidin biotinylated horseradish peroxidase (1:100 dilution, Amersham Pharmacia Biotech, Piscataway, NJ, U.S.A.) at room temperature. Color was developed using diaminobenzidine (1:10 dilution, Pierce Chemical, Rockford, IL, U.S.A.) as the chromogen. The sections were viewed at $200 \times$ and $1000 \times$ magnification using an Olympus Provis microscope.

$\boldsymbol{C O X}$-2. Sections adjacent to those used for albumin staining were mounted on Superfrost + slides (Menzel-Glaser, Braunschweig, Germany) and air dried overnight. The sections were rehydrated and boiled in citric acid buffer $(0.01 \mathrm{M}, \mathrm{pH} 6)$ using a microwave oven three times each for $5 \mathrm{~min}$ each time to retrieve antigens. Nonspecific binding was first blocked by incubating the section in 5\% normal goat serum in PBS $(0.1 \mathrm{M}$, $\mathrm{pH}$ 7.4) for $45 \mathrm{~min}$ at room temperature. The staining procedures were then performed as described above using a polyclonal COX-2 primary antibody raised in rabbits against murine COX-2 (Cayman Chemical, Ann Arbor, MI, U.S.A.) at a final dilution of 1:200. The sections were examined as above. The number of blood vessels intimately associated with COX2-positive cells were counted and the results expressed relative to the total number of blood vessels observed in each field of view.

Identification of perivascular monocytes. Cells of monocyte origin were identified by lectin immunocytochemistry. Blocks of the perfusion-fixed fetal brain were embedded in paraffin. Sections $(10 \mu \mathrm{m})$ were mounted on Superfrost+ slides. Antigen retrieval was first performed by boiling the sections in citric acid buffer three times each for 5 min each time. Nonspecific binding was blocked by incubating with $5 \%$ normal goat serum, $2 \%$ BSA, and $0.3 \%$ Triton X-100 in PBS for $30 \mathrm{~min}$ at room temperature. The sections were then incubated overnight with a peroxidase-labeled isolectin $\mathrm{B}_{4}$ from Bandeiraea simplicifolia (Sigma Chemical) at a final dilution of 1:200 in PBS. After washing in PBS, color was developed using diaminobenzidine as the chromogen. Adjacent sections were also stained using hematoxylin-eosin (H\&E).

\section{Data Analysis}

Data are presented as mean \pm SEM. Two-way repeated measures ANOVA was used to analyze the differences of blood gas parameters between saline and LPS treatment groups $(p<0.05)$. Where the ANOVA indicated significant differences between treatment and time, a least square difference test was used posthoc to identify significant differences between the treatment groups at each sampling time. The MannWhitney $U$ test was used to identify differences between the number of COX-2-positive blood vessels in each brain region of the LPS and saline treatment groups.

\section{RESULTS}

Blood gases, $\boldsymbol{p H}$. When given as a bolus injection into the jugular vein over 2-3 min, LPS resulted in a significant decrease of arterial $\mathrm{O}_{2}$ saturation, $\mathrm{Po}_{2}$, and $\mathrm{pH}$, and a significant increase of arterial $\mathrm{PCO}_{2}$ (Fig. 1). The $\mathrm{pH}$ reached its lowest value $4 \mathrm{~h}$ after LPS administration and then recovered; at $12 \mathrm{~h}$ after treatment the values were not different from those observed in the saline-treated fetuses (Fig. 1C). $\mathrm{PCO}_{2}$ had increased significantly by $2 \mathrm{~h}$ and remained significantly higher than values for the saline-treated control group until $30 \mathrm{~h}$ after LPS treatment (Fig. 1D). Arterial $\mathrm{O}_{2}$ saturation and $\mathrm{Po}_{2}$ decreased rapidly between 1 and $2 \mathrm{~h}$ after treatment, and remained slightly but significantly below the values observed in the saline-treated fetuses for the remainder of the experimental period (Fig. 1, $A$ and $B$ ). All fetuses survived the 24 or $48 \mathrm{~h}$ posttreatment period.

COX-2 mRNA expression. COX-2 mRNA was measured in cerebral cortex and cerebellum at 24 and $48 \mathrm{~h}$ after LPS administration, compared with saline-treated fetuses. Samples from three fetuses in each group were run, together with standards, on a 10-lane gel (Fig. 2). The levels of COX-2 mRNA in saline-treated control brains obtained at 24 or $48 \mathrm{~h}$ after treatment were not different from the levels observed in cortex and cerebellum from untreated fetuses of the same gestational age when these were run on the same gel (data not shown). COX-2 mRNA was increased significantly (relative to GAPDH mRNA) in both regions of the brain compared with the saline-treated fetuses. The increase was significant at $48 \mathrm{~h}$ in the cortex (Fig. 2A), and at 24 and $48 \mathrm{~h}$ in the cerebellum (Fig. 2B).

COX-2 protein immunoreactivity. LPS treatment resulted in the appearance of COX-2 immunoreactivity in cells closely associated with blood vessels in most regions of the brain. Under low-power magnification it was possible to trace blood vessels over long distances through the sections due to the presence of these immunoreactive perivascular cells (Fig. 3, $B$ and $F$ ). Under higher power, the COX-2 immunopositive cells were seen to be located around the perimeter of blood vessels and in close proximity to the blood vessel wall (Fig. 3, D and $H$ ). These cells were almost always rounded in shape and the COX-2 staining was present throughout the cytoplasm. Blood vessels displaying COX-2 immunoreactive perivascular cells were found in all the major regions of the brain after LPS treatment, where the number of cells was significantly more than observed in the saline-treated fetuses (Table 1; Fig. 3, $A$, $C, E$, and $G$ ). The exception was the subcallosal bundle in the region of the caudate nucleus, where, in the saline-treated fetuses, COX-2-positive cells were found adjacent to approximately $12 \%$ of the blood vessels. Some immunoreactive COX-2 cells not associated with blood vessels were observed throughout sections from both LPS- and saline-treated fetuses (Fig. 3, A, B, E , and $F$, arrowheads). These cells had the appearance of neuronal cell bodies, which agrees with the 

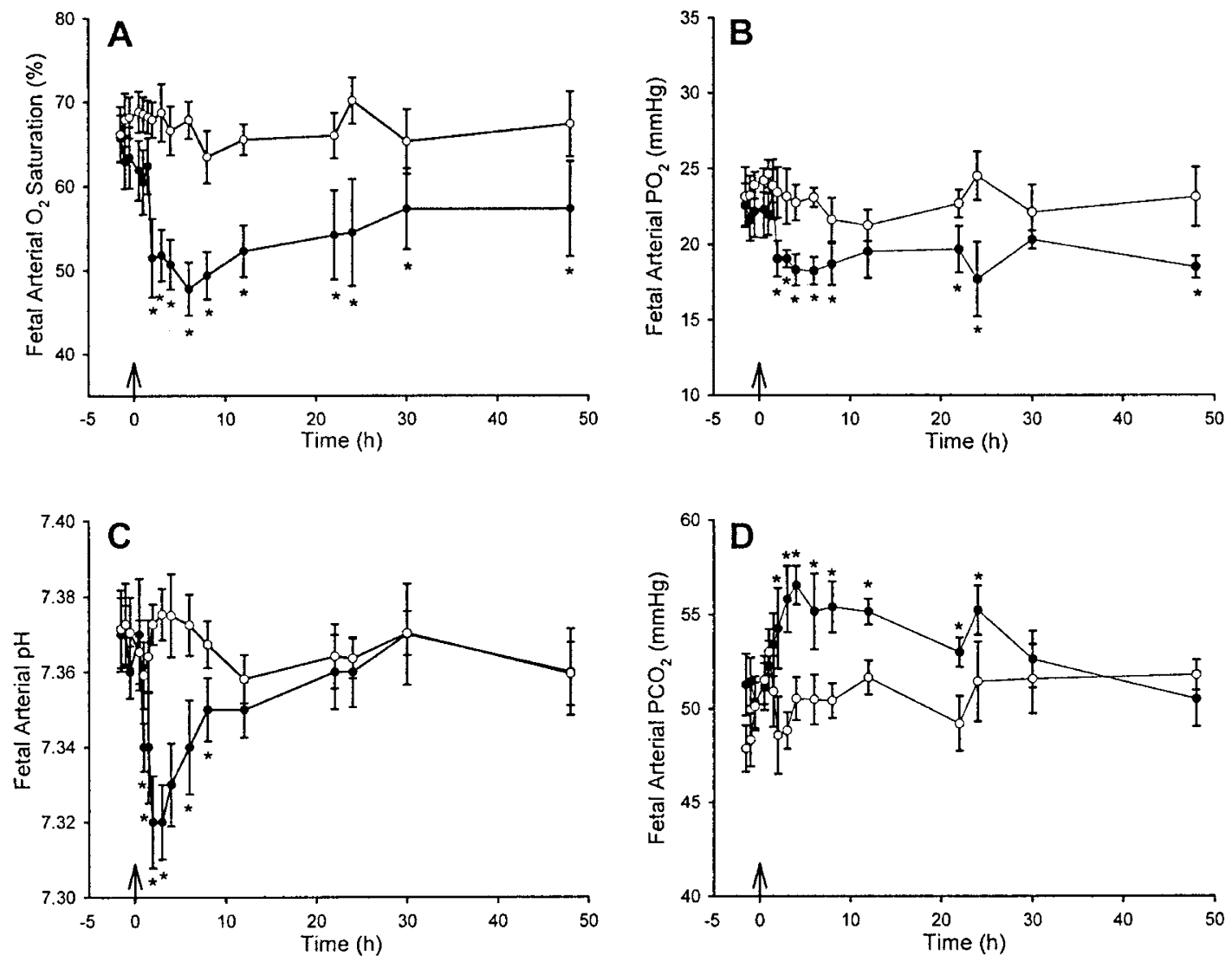

Figure 1. Fetal arterial blood gas parameters throughout $48 \mathrm{~h}$ after bolus i.v. injection of either $0.1 \mu \mathrm{g} / \mathrm{kg}$ LPS or saline. There were no differences between the LPS (solid circles) and saline (open circles) groups at beginning of the experiment, and no significant changes in the saline-treated group with time for all parameters. Asterisks show significant changes between LPS and saline groups $(p<0.05)$; results shown as mean \pm SEM; $n=5$ throughout.

finding that COX-2 is constitutively expressed by some neurons in the brain (20).

Albumin immunoreactivity. Twenty-four hours after LPS treatment, immunoreactive albumin was observed in most regions of the brain (Fig. 4), and in the majority of fetuses (Table 2). Intense albumin staining was observed in the brain parenchyma adjacent to blood vessels in the LPS-treated fetuses (Fig. 4, $B, D, F$, and $H$ ). In contrast, albumin staining was rarely observed anywhere in the brains of the saline-treated fetuses. Examples for the cerebral cortex showing the absence of albumin staining are shown in Figure $3, A, C, E$, and $G$. In cerebellum, albumin staining was not observed in the extracellular space adjacent to blood vessels, but was found in the cytoplasm of Purkinje cells in the LPS-treated fetuses (data not shown).

Lectin histochemistry and $H \& E$ staining. Dense aggregations of lectin-positive cells were observed around blood vessels in the subcallosal and subventricular white matter (Fig. $5 B$ ). These lectin-positive cells were generally large and rounded, had the appearance of macrophages, and were observed only in the brains of LPS-treated fetuses (Fig. 5, $B$ and $D)$. No lectin-positive cells of this size and shape were observed in the brains of the saline-treated fetuses (Fig. 5, $A$ and $C$ ), nor were they observed in gray matter from either LPS- or saline-treated fetuses. H\&E-stained sections also revealed large, rounded cells infiltrated parenchyma that had the morphologic characteristics of macrophages (Fig. 6B). Activated microglia were identified as smaller, rounded lectin-positive cells, usually with small processes extending from the cell body. These small cells were usually more distant from blood vessels and were found throughout the white matter. Only a small number of these small, intensely lectin-positive cells were observed in the tissue from the control fetuses.

\section{DISCUSSION}

The three major findings of this study can be summarized as follows. Firstly, LPS treatment induced COX-2 protein expression in cells intimately associated with small blood vessels in the fetal brain, which, on the basis of their shape and distribution, were likely to be either perivascular macrophages or pericytes. Secondly, albumin extravasation was observed in gray and white matter throughout the brains of LPS-treated fetuses, except for the cerebellum, where albumin staining was associated with Purkinje cells. Thirdly, large lectin-positive cells, which had the appearance of peripheral macrophages, were observed in the subventricular white matter of LPStreated fetuses.

The dose of LPS used in this experiment was determined after pilot experiments showed that doses of $1 \mu \mathrm{g}$ or more were often fatal in late gestation fetal sheep, with fetal death occurring 18-24 $\mathrm{h}$ after LPS administration (27; Nicholls T, Walker $\mathrm{D}$, unpublished observations). In the current study, we used a lower dose of LPS $(0.1 \mu \mathrm{g} / \mathrm{kg})$ to produce a mild fetal immune 
(A)
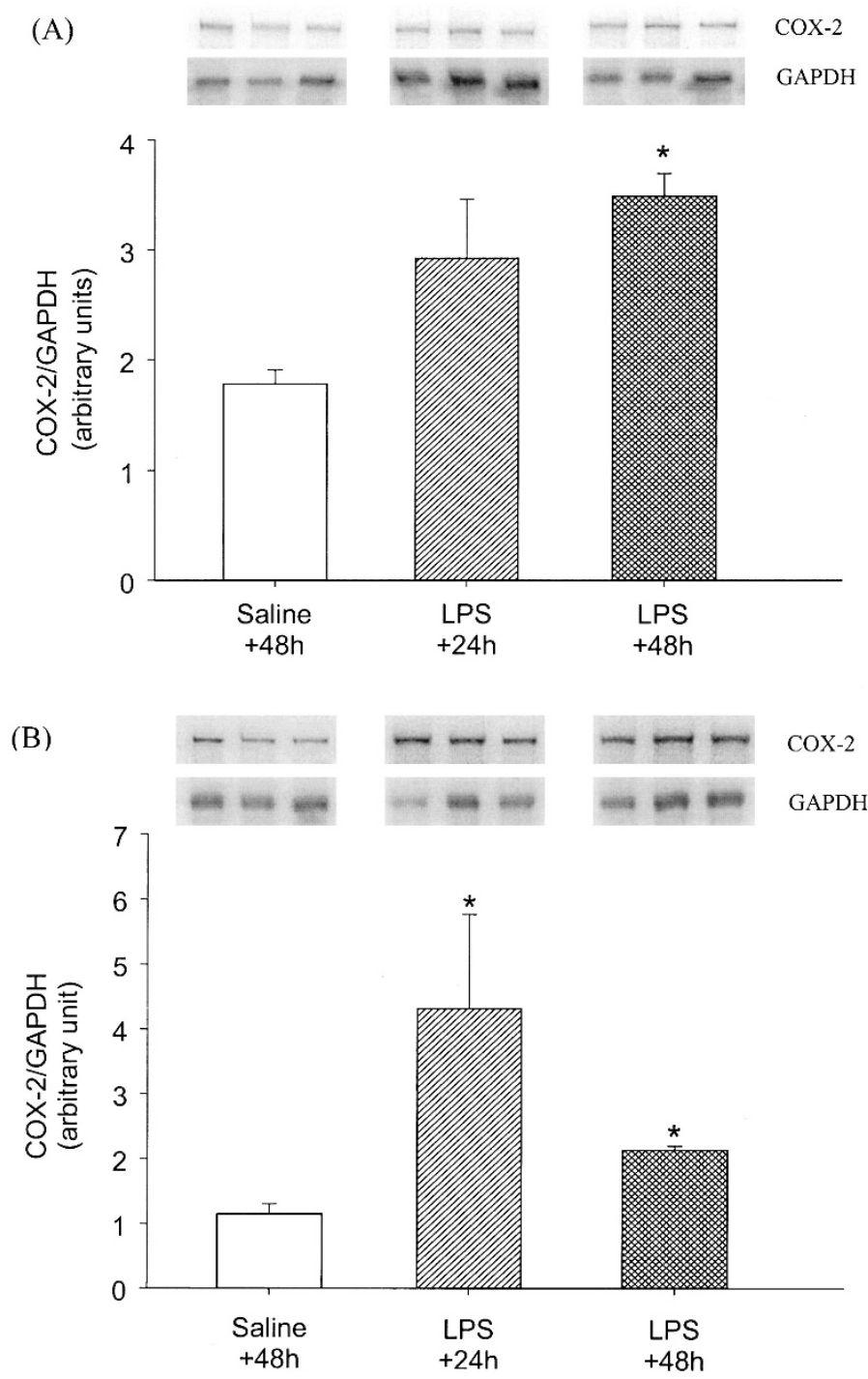

Figure 2. COX-2 mRNA expression in $(A)$ cortex and $(B)$ cerebellum at 24 and $48 \mathrm{~h}$ after treatment with LPS $(0.1 \mu \mathrm{g} / \mathrm{kg})$ compared with the same regions obtained from fetuses $48 \mathrm{~h}$ after saline treatment; $n=3$, each group. The upper panels show gel images of the RNase-protected bands for COX-2 and GAPDH mRNA, and the lower panels show the results (mean \pm SEM) from the densitometric analysis plotted as the ratio of intensity between the two bands. Asterisks indicate significant differences between the saline- and LPS-treated values; $p<0.05$.

response and ensure that all fetuses were alive at 24 or $48 \mathrm{~h}$ after the treatment. The LPS treatment caused fetal hypoxemia and acidosis, which was greatest 3-4 $\mathrm{h}$ after treatment, and although there was complete recovery of arterial $\mathrm{pH}$, a mild but significant degree of fetal hypoxemia was present for the remainder of the $24 \mathrm{~h}$ experimental period. The presence of this persisting hypoxemia suggests that placental perfusion may have been affected by the LPS. Except for the mild hypoxemia, all fetuses were in a stable physiologic condition at the time of autopsy.

There was an increase of COX-2 mRNA in the cerebral cortex and cerebellum at 24 and $48 \mathrm{~h}$ after the LPS treatment, and immunohistochemistry showed that COX-2 protein expression was also increased in many brain regions. Similar findings have been made in brains of adult rodents after
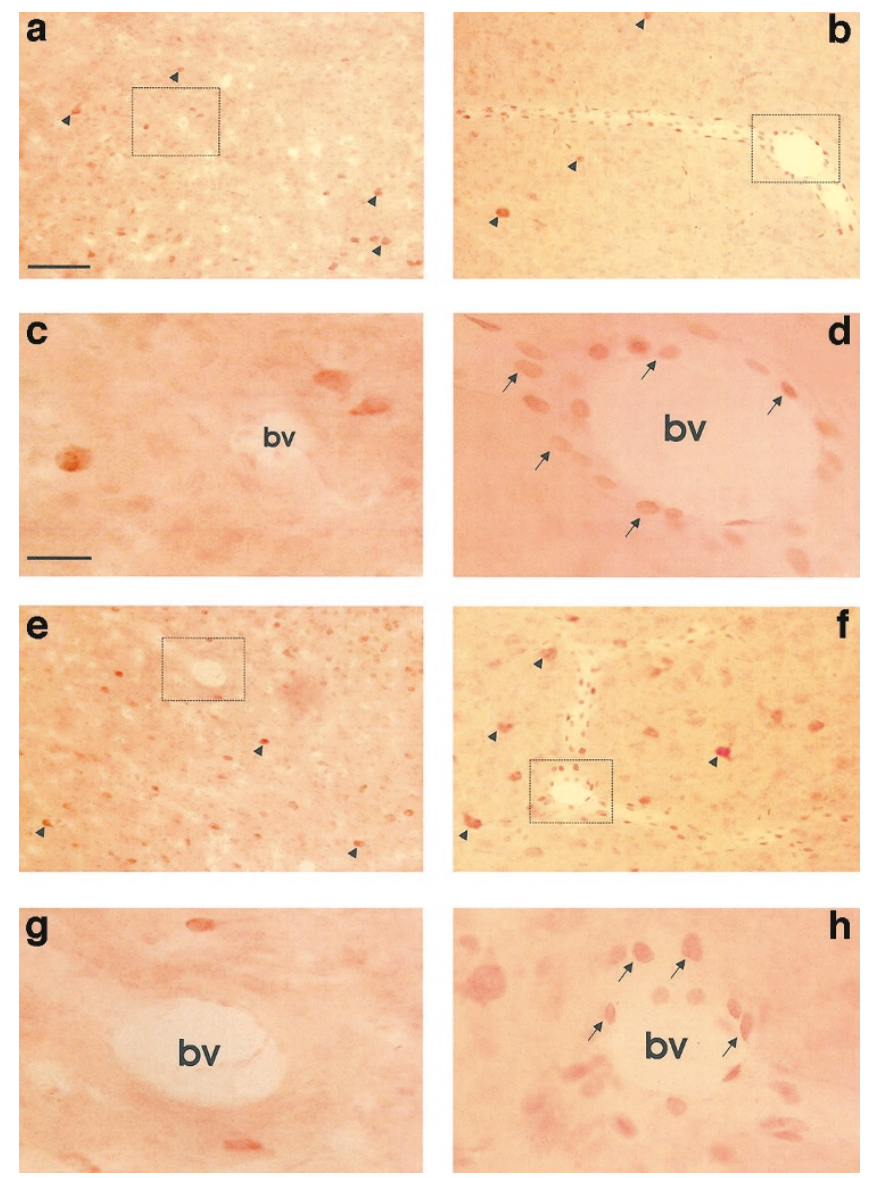

Figure 3. COX-2 immunoreactivity in white matter tracts $(A-D)$ and gray matter $(E-H)$ of the cerebral cortex $24 \mathrm{~h}$ after LPS (right panels) or saline (left panels) treatments. COX-2-positive cells adjacent to the course of a blood vessel can be seen at low-power magnification $(200 \times)$ in $B$ and $F$, and at higher magnification $(1000 \times)$ are seen to encircle the blood vessel $(b v)(D$ and $H$ ). No perivascular COX-2 immunoreactivity was observed in the salinetreated cortex $(A, C, E$, and $G)$. COX-2 positive cells, probably neurons (arrowheads), were observed in fetuses from both groups. Scales: $A, B, E$, and $F=100 \mu \mathrm{m}$, as shown by bar in $A ; C, D, G$, and $H=20 \mu \mathrm{m}$, as shown by bar in $C$.

Table 1. Perivascular COX-2 immunoreactivity in the fetal brain

\begin{tabular}{lcc}
\hline & LPS treated & Saline treated \\
\hline Cortex & & \\
$\quad$ Gray matter & $63.9 \pm 4.6^{*}$ & $3.8 \pm 1.6$ \\
$\quad$ White matter & $48.7 \pm 7.7^{*}$ & $4.0 \pm 1.4$ \\
Thalamus & $61.0 \pm 4.0^{*}$ & 0 \\
Hypothalamus & $60.8 \pm 5.5^{*}$ & 0 \\
Corpus callosum and fornix & $14.0 \pm 5.5^{*}$ & 0 \\
Hippocampus & $54.8 \pm 9.0^{*}$ & $0.7 \pm 0.7$ \\
Midbrain & $56.4 \pm 6.1^{*}$ & $2.5 \pm 1.4$ \\
Subcallosal bundle & $52.2 \pm 8.0$ & $12.0 \pm 6.1$ \\
Cerebellum & $38.0 \pm 4.1^{*}$ & 0 \\
\hline
\end{tabular}

The percentage of blood vessels counted in each brain region that was associated with perivascular COX-2 immunoreactive cells $24 \mathrm{~h}$ after either LPS treatment $(n=5)$ or saline treatment $(n=5)$. Data shown as mean $( \pm$ SEM).

* Significant difference between the LPS and saline groups; $p<0.05$, Mann-Whitney $U$ test.

peripheral LPS administration $(10,15,18)$, although it should be noted that in these studies the increased COX-2 expression was not as prolonged [either $7 \mathrm{~h}(10)$ or $15 \mathrm{~h}(15)$ ] as it was in 

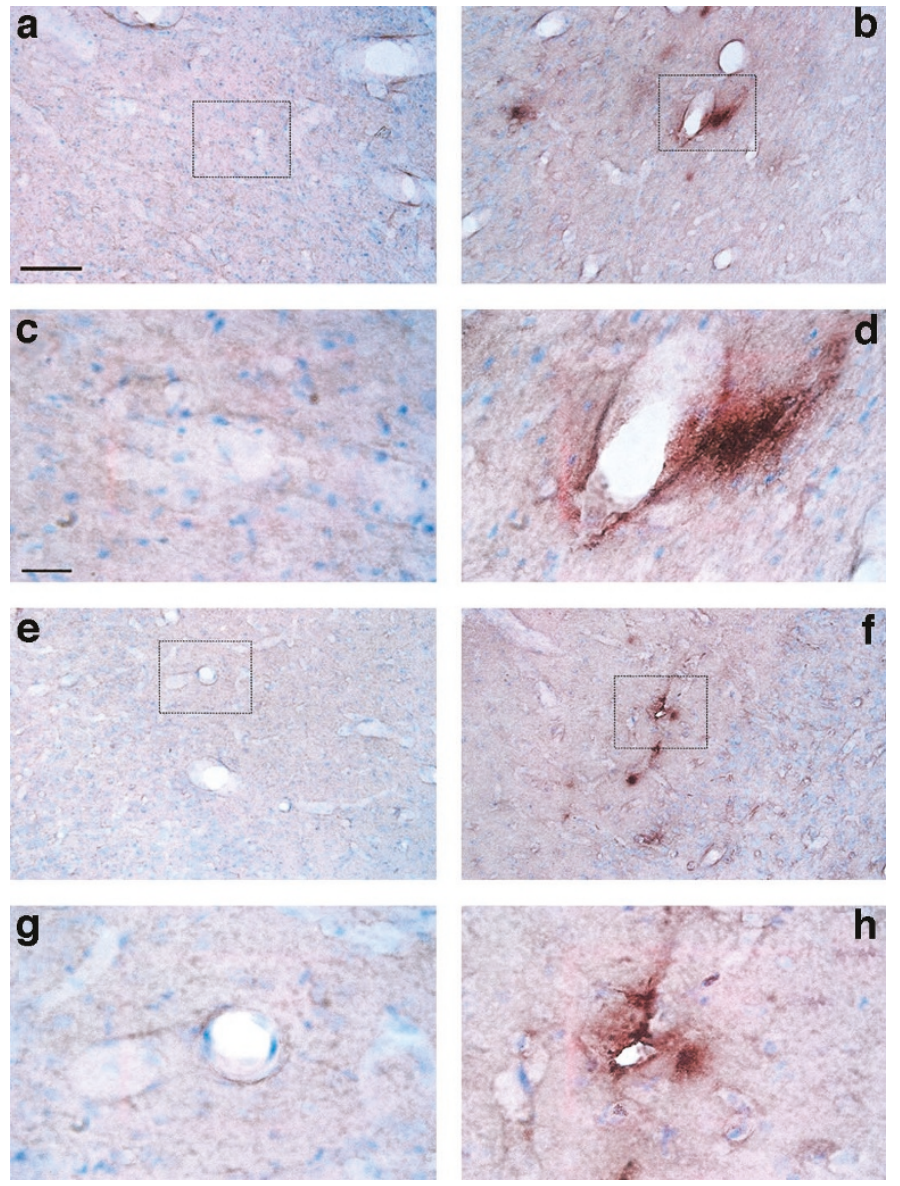

Figure 4. Albumin immunoreactivity in white matter tracts $(A-D)$ and gray matter $(E-H)$ of the cerebral cortex $24 \mathrm{~h}$ after LPS (right panels) or saline (left panels) treatments. Intense staining for endogenous ovine plasma albumin was seen adjacent to blood vessels; $D$ and $H$ are higher magnifications of the boxed areas shown in $B$ and $F$, respectively. No albumin penetration was observed in saline-treated brains $(A, C, E$, and $G)$. Scales: $A, B, E$, and $F=100 \mu \mathrm{m}$, as shown by bar in $A ; C, D, G$, and $H=20 \mu \mathrm{m}$, as shown by bar in $C$.

Table 2. Intraparenchymal albumin in LPS-and saline-treated fetuses

\begin{tabular}{lcc}
\hline & LPS treated & Saline treated \\
\hline Cortex & & \\
$\quad$ Gray matter & $5 / 5$ & $0 / 5$ \\
$\quad$ White matter & $4 / 5$ & $0 / 5$ \\
Thalamus & $5 / 5$ & $1 / 5$ \\
Hypothalamus & $5 / 5$ & $1 / 5$ \\
Corpus callosum and fornix & $2 / 4$ & $0 / 3$ \\
Hippocampus & $3 / 4$ & $0 / 4$ \\
Midbrain & $4 / 5$ & $1 / 4$ \\
Subcallosal bundle & $2 / 5$ & $0 / 5$ \\
Cerebellum (whole) & $0 / 5$ & $0 / 5$ \\
\hline
\end{tabular}

Number of fetuses per treatment group in which albumin was identified within the brain, adjacent to a blood vessels. A minimum of two sections from each brain region was examined for each fetus.

the present study where robust expression was present $24 \mathrm{~h}$ after treatment. Whether this relates to differences between adult and developing brain or is a species difference will require further study.

COX-2 is constitutively expressed in the brain and contributes to basal PG production $(20,31,32)$. These finding are consistent with the strong basal level of mRNA expression we observed in tissue from the fetal lamb cerebellum and cortex. Induction of COX-2 is considered responsible for most of the increased PG production in the brain after systemic infection (12), although some recent studies suggest that COX-1 may also contribute to PG production, particularly in the cerebellum, after exposure to inflammatory cytokines (32). It is likely that the response we observed in the fetal brain results from the increase of cytokines in the circulation, particularly IL- $1 \beta$ and IL-6, and their subsequent actions on endothelial cells. Cerebral endothelial cells contain receptors for these cytokines (8), and cells obtained from preterm human neonates, at a similar developmental age to the fetal lambs used in the present studies, respond to IL- $1 \beta$ with a marked increase in COX-2 activity (32). LPS also has prolonged and more delayed effects on some transcription factors and target genes (33), particularly on NO production (34), which might be responsible for the more protracted effects on COX-2 expression seen in these experiments compared with the adult rodent brain. For example, NO production induced by LPS is known to lead to increased synthesis of COX-2 mRNA (34), and also directly activates COX-2 enzyme through its oxidative capacity to modify the structure of the enzyme. NO also reacts with superoxide anions to form peroxynitrate, leading to enhanced COX-2 activity (34). Thus, activation of COX-2 in the parenchyma of the fetal sheep brain may be secondary to the initial activation of COX-2 in perivascular cells by cytokines or endotoxin in the circulation.

The distribution of the COX-2-expressing cells in the fetal sheep brain after LPS is consistent with previous reports on LPS effects in the adult rat brain $(6,20,35)$. The predominant effect was on perivascular cells rather than neurons. However, identification of the particular cells responding to LPS remains problematic because, in our hands, antibodies that label microglia and macrophages (e.g. OX42, ED1, ED2) do not work well in the ovine fetal brain (unpublished observations). Based upon their distribution and rounded morphology, Schlitz and Sawchenko (35) concluded that COX-2-positive perivascular cells were endothelial cells, although similar observations by Minghetti et al. (36) led them to conclude that COX-2/ED-1 reactivity identified a "perivascular" subpopulation of macrophage/microglial cells. Polygonal, multipolar cells have been identified as perivascular microglia on the basis of their reactivity to the macrophage differentiation antigen ED2 (35). In the present study, the great majority of the COX-2-bearing cells were rounded in shape and closely associated with blood vessels. Similar findings have been made for human cerebrovascular endothelial cells (32). The lectin staining also identified some perivascular cells that were like the polygonal, multipolar cells described by Schlitz and Sawchenko (35), but we were unable to distinguish whether they were perivascular microglia or macrophages that had penetrated the cerebrovascular boundary.

The presence of albumin in many brain regions indicates that the LPS treatment had caused increased permeability of the BBB sufficient to allow penetration of plasma proteins into brain. The presence of albumin near blood vessels is also consistent with alteration of the integrity of vascular structure 

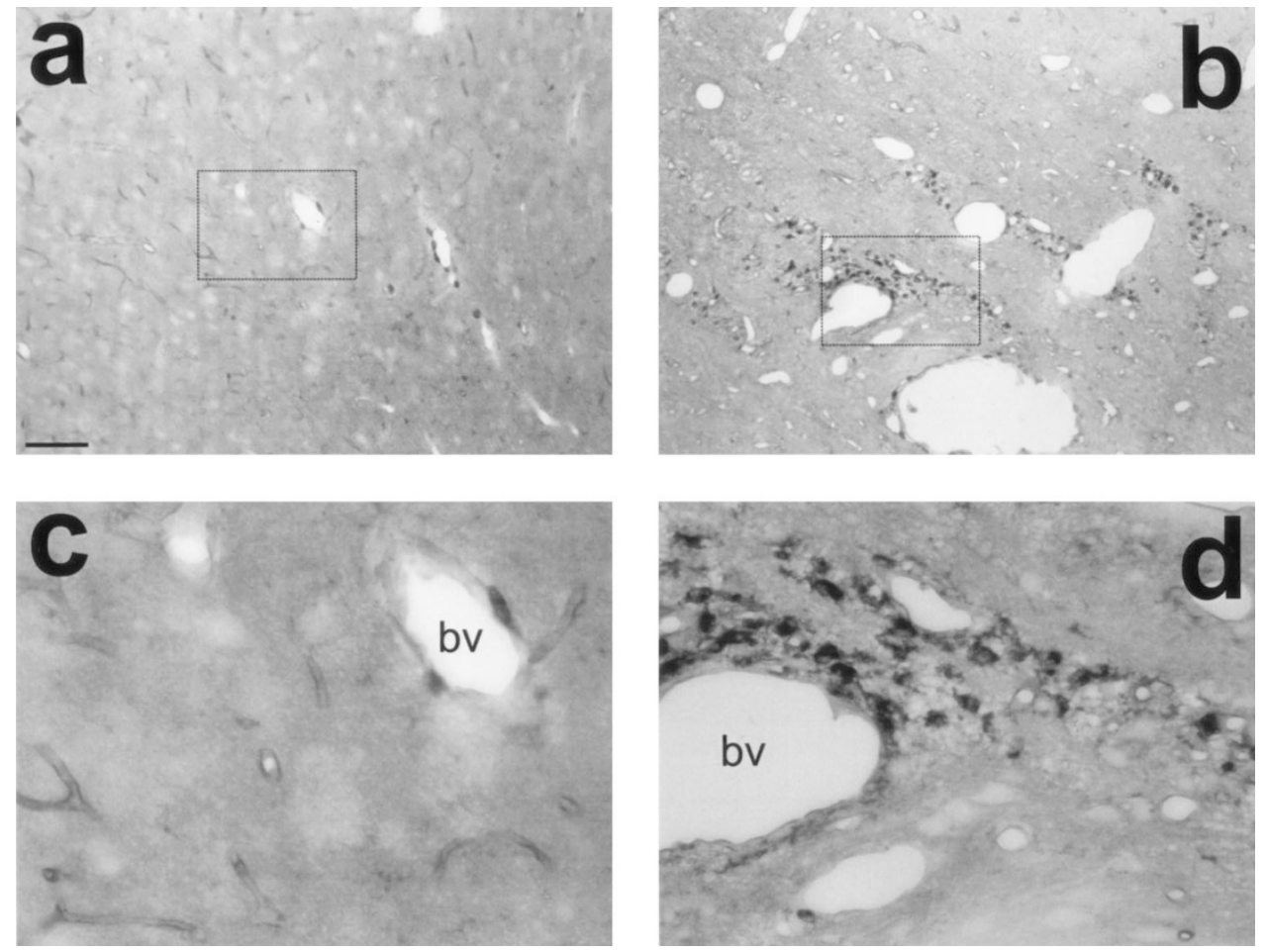

Figure 5. Lectin histochemistry in subventricular white matter $24 \mathrm{~h}$ after LPS (right panels) and saline (left panels) treatments. Heavily stained lectin-positive cells are located around blood vessels $(b v)$ in the LPS-treated fetal brain $(B)$, but not observed in the saline-treated fetal brain $(A)$. $C$ and $D$ are higher magnifications views of boxed areas shown in $A$ and $B$, respectively. Scales: $A$ and $B=100 \mu \mathrm{m}$ and $C$ and $D=50 \mu \mathrm{m}$, as shown by bar in $A$.
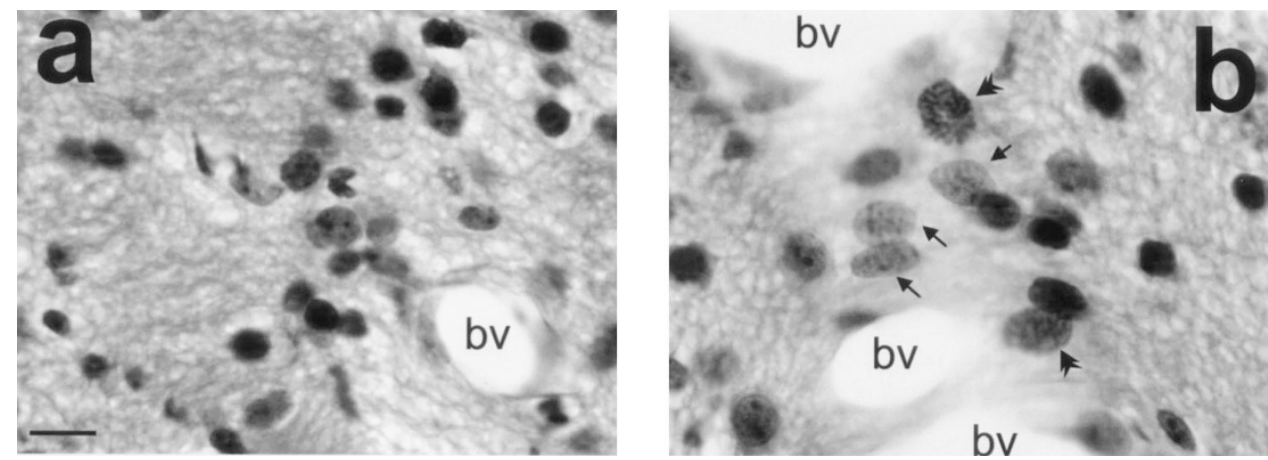

Figure 6. Photomicrographs showing H\&E-stained sections of a control $(A)$ and an LPS-treated fetus $(B)$. The brain sections stained with H\&E were immediately adjacent to the sections stained for lectin. The thin arrows in $B$ show macrophage-like cells in subventricular white matter $24 \mathrm{~h}$ after LPS treatment. In LPS-treated brains, macrophages were observed in the parenchyma located close to blood vessels $(b v)$. Monocytes were also observed in LPS-treated brain as shown by double arrowheads $(B)$. Macrophages and monocytes were not found in the parenchyma of brains from the saline-treated group $(A)$. Scale bar $=$ $20 \mu \mathrm{m}$, as shown by bar in $A$.

that allowed the extravasation of blood-borne material into the brain. The precise timing of this event and how long it might have lasted cannot be determined from these experiments, but whether it is a transient event or the result of longer and more persistent damage to the BBB will be important to establish. Perivascular accumulation of proteinaceous material was observed many years ago in human neonatal postmortem brains showing leucoencephalopathy and focal necroses (37), and in neonatal feline brain after endotoxin exposure (38). Thus, this form of vasculopathy may be one of the consequences of infection. As COX-2 inhibition, or pretreatment with dexamethasone (which suppresses PG production), effectively blocks increases of BBB permeability $(21,22)$, PG production either by cerebrovascular endothelial cells or by cells in close proximity to them may be responsible for the increase of BBB permeability to plasma proteins. In a model of immobilization stress in rats, albumin extravasation occurred in hypothalamus, hippocampus, brainstem, and cerebellum, but not in cortex and striatum, indicating regional differences in the sensitivity of the BBB to stress (39).

In this study, the response of the cerebellum to systemic LPS treatment was different from other regions of the fetal brain. Although there was an increase of COX-2 mRNA, and increase of immunoreactive protein expression associated with small blood vessels, there was no evidence of albumin extravasation into the parenchyma of the cerebellum. It is possible that albumin extravasation had occurred earlier than in the other brain regions, or that endothelial tight junction proteins are less 
effected by cytokines or increased PG in the cerebellum. The cell bodies of Purkinje neurons were also strongly positive for albumin immunoreactivity, an effect of LPS treatment not observed elsewhere in the fetal brain. Whereas in situ synthesis of albumin by neurons and blood-to-brain transfer of plasma proteins are processes present in the immature brain, these are not present in the fetal sheep brain after approximately $120 \mathrm{~d}$ gestation (40). Albumin uptake has been observed in cultured neurons, where it appears to influence glucose utilization, increase glutamate synthesis, and suppress apoptosis, suggesting that it promotes neuronal survival (41).

We also observed large, lectin-positive cells, particularly in subventricular white matter, in the close vicinity of blood vessels. These cells were identified by morphology as macrophages. This is an important observation because it suggests that macrophage penetration into white matter occurs at lower doses of LPS required to provoke the response elsewhere in the brain. Macrophages respond to a wide range of microbial products such as LPS using a toll-like receptor on their surface (33), initiating host-defense mechanisms by release of cytokines, particularly IL- 1 and TNF- $\alpha$. Macrophage infiltration is a well-defined response to systemic and CNS infections in the adult brain $(26,42)$, and the presence of activated monocytes of peripheral and in situ origin (i.e. microglia) that release proinflammatory cytokines has been suggested as a factor contributing to white matter damage in the preterm human newborn (43). The movement of macrophages into the brain can occur across an intact BBB (26), and the increased numbers of monocytic cells in the brain may not require breakdown of the $\mathrm{BBB}$ in response to infection. In contrast, albumin penetration, which was present in both gray and white matter regions of the fetal brain in this study, is likely to require the separation of tight junctions between the endothelial cells.

A further implication of the results of this study is that the relatively prolonged changes of $\mathrm{BBB}$ permeability and $\mathrm{COX}-2$ expression that follow a single, brief exposure to endotoxin could potentiate subsequent effects of stress on the perinatal brain, for example, by the asphyxia or hypoxia that often occurs during birth. Although it is clear that maternal infection is not always associated with perinatal brain damage and, conversely, many infants who develop cerebral palsy are born to mothers without recognized infection (1), the results of this study suggest that cytotoxic substances may be able to enter the fetal brain over a reasonably long time after LPS exposure. Our recent observation (44) that the placenta can release increased amounts of quinolinic acid, a potentially neurotoxic metabolite of tryptophan, into the fetal circulation indicates that the fetal brain may be exposed to this or other cytotoxic and proinflammatory substances that accumulate in fetal blood. Our findings also raise the question of whether intrauterine or fetal infection during pregnancy requires treatment to inhibit $\mathrm{BBB}$ permeability changes and COX-2 expression in the fetus, even after the systemic signs of the infection have resolved.

Acknowledgments. The authors thank Alex Satragno for his expert help with the surgical procedures. We also thank Dr. K. Dziegielewska for invaluable help and advice with the immunohistochemistry and histology.

\section{REFERENCES}

1. Grether JK, Nelson KB 1997 Maternal infection and cerebral palsy in infants of normal birth weight. JAMA 278:207-211

2. Van Hoeven KH, Anyaegbunam A, Hochster H, Whitty JE, Distant J, Crawford C, Factor SM 1996 Clinical significance of increasing histologic severity of acute inflammation in the fetal membranes and umbilical cord. Pediatr Pathol Lab Med 16:731-744

3. Baud O, Emilie D, Pelletier E, Lacaze-Masmonteil T, Zupan V, Fernandez H, Dehan M, Frydman R, Ville Y 1999 Amniotic fluid concentrations of interleukin-1beta, interleukin- 6 and TNF- $\alpha$ in chorioamnionitis before 32 weeks of gestation: histological associations and neonatal outcome. Br J Obstet Gynaecol 106:72-77

4. Kim CJ, Yoon BH, Romero R, Moon JB, Kim M, Park S-S, Chi JG 2001 Umbilical arteritis and phlebitis mark different stages of the inflammatory response. Am J Obstet Gynecol 185:496-500

5. Dammann O, Leviton A 1998 Infection remote from the brain, neonatal white matter damage, and cerebral palsy in the preterm infant. Semin Pediatr Neurol 5:190-201

6. Elmquist JK, Breder CD, Sherin JE, Scammell TE, Hickey WF, Dewitt D, Saper CB 1997 Intravenous lipopolysaccharide induces cyclooxygenase 2-like immunoreactivity in rat brain perivascular microglia and meningeal macrophages. J Comp Neurol 381:119-129

7. Banks WA, Kastin AJ, Durham DA 1989 Bidirectional transport of interleukin-1 alpha across the blood-brain barrier. Brain Res Bull 23:433-437

8. Engblom D-D 2002 Prostaglandins as inflammatory messengers across the bloodbrain barrier. J Mol Med 80:5-15

9. Moore SA, Spector AA, Hart MN 1988 Eicosanoid metabolism in cerebromicrovascular endothelium. Am J Physiol 254:C37-C44

10. Cao C, Matsumura K, Yamagata K, Watanabe Y 1995 Induction by lipopolysaccharide of cyclooxygenase-2 mRNA in rat brain; its possible role in the febrile response. Brain Res 697:187-196

11. Elmquist JK, Scammell TE, Saper CB 1997 Mechanisms of CNS response to systemic immune challenge: the febrile response. Trends Neurosci 20:565-570

12. Kennedy BP, Chan CC, Culp SA, Cromlish WA 1993 Cloning and expression of prostaglandin synthase (cyclooxygenase)-2 cDNA. Biochem Biophys Res Commun 197:494-500

13. Norton JL, Adamson SL, Bocking AD, Han VK 1996 Prostaglandin-H synthase-1 (PGHS-1) gene is expressed in specific neurons of the brain of the late gestation ovine fetus. Brain Res Dev Brain Res 95:79-96

14. Van Dam AM, Brouns M, Man AHW, Berkenbosch F 1993 Immunocytochemical detection of prostaglandin E2 in microvasculature and in neurons of rat brain after administration of bacterial endotoxin. Brain Res 613:331-336

15. Breder CD, Saper CB 1996 Expression of inducible cyclooxygenase mRNA in the mouse brain after systemic administration of bacterial lipopolysaccharide. Brain Res 713:64-69

16. Cao C, Matsumura K, Yamagata K, Watanabe Y 1997 Involvement of cyclooxygenase- 2 in LPS-induced fever and regulation of its mRNA by LPS in the rat brain. Am J Physiol 272:R1712-R1725

17. Maloney CG, Kutchear WA, Albertine KH, McIntyre TM, Prescott SM, Zimmerman GA 1998 Inflammatory agonist cyclooxygenase type 2 expression by human neutrophils. J Immunol 160:1402-1410

18. Quan N, Whiteside M, Herkenham M 1998 Cyclooxygenase 2 mRNA expression in rat brain after peripheral injection of lipopolysaccharide. Brain Res 802:189-197

19. Yamagata K, Andreasson KI, Kaufmann WE, Barnes CA, Worley PF 1993 Expression of a mitogen-inducible cyclooxygenase in brain neurons: regulation by synaptic activity and glucocorticoids. Neuron 11:371-386

20. Breder CD, Dewitt D, Kraig RP 1995 Characterization of inducible cyclooxygenase in rat brain. J Comp Neurol 355:296-315

21. Tsao N, Hsu H-P, Lei H-Y 1999 TNF- $\alpha$ induced cyclooxygenase 2 not only increases the vasopermeability of blood-brain barrier but also enhances the neutrophil survival in Escherichia coli-induced brain inflammation. Prostaglandins Other Lipid Mediat 57:371-382

22. Minami T, Okazaki J, Kawabata A, Kawaki H, Okazaki Y, Tohno Y 1998 Roles of nitric oxide and prostaglandins in the increased permeability of the blood-brain barrier caused by lipopolysaccharide. Environ Toxicol Pharmacol 5:35-41

23. Saunders NR 1992 Ontogenetic development of brain barrier mechanisms. In: Bradbury MWB (ed) Handbook of Experimental Pharmacology. Springer-Verlag, Berlin, pp 327-369

24. Saunders NR, Habgood MD, Dziegielewska K 1999 Barrier mechanisms in the brain II. Immature brain. Clin Exp Pharmacol Physiol 26:85-91

25. Stonestreet BS, Sadowska GB, McKnight AJ, Patlak C, Petersson KH 2000 Exogenous and endogenous corticosteroids modulate blood-brain barrier development in the ovine fetus. Am J Physiol Regul Integr Comp Physiol 279:R468-R477

26. Perry VH, Anthony DC, Bolton SJ, Brown HC 1997 The blood-brain barrier and the inflammatory response. Mol Med Today 3:335-341

27. Schlafer DH, Yuh B, Foley TH, Elssaser TH, Sadowsky D, Nathanielsz PW 1994 Effect of salmonella endotoxin administered to the pregnant sheep at 133-142 days gestation on fetal oxygenation, maternal and fetal ACTH and cortisol, and maternal plasma TNF- $\alpha$ concentration. Biol Reprod 50:1297-1302

28. Sehic E, Szekely M, Ungar AL, Oladehin A, Blatteis CM 1996 Hypothalamic prostaglandin E2 during lipopolysaccharide-induced fever in guinea pigs. Brain Res Bull 39:391-399

29. Nicholls T, Nitsos I, Walker DW 1999 Tryptophan metabolism in pregnant sheep: increase fetal kynurenine production in response to maternal tryptophan loading. Am J Obstet Gynecol 181:1452-1460 
30. Zhang V, O'Sullivan M, Hussain H, Roswit WT, Holtzman MJ 1996 Molecular cloning, functional expression and selective regulation of prostaglandin $\mathrm{H}$ synthase-2. Biochem Biophys Res Commun 227:499-506

31. Hume DA, Underhill DM, Sweet MJ, Ozinsky AO, Liew FY, Aderem A 2001 Macrophages exposed continuously to lipopolysaccharide and other agonists that act via toll-like receptors exhibit a sustained and additive activation state. BMC Immunol 2:11

32. Peri KG. Hardy P. Li DY. Varma DR. Chemtob S 1995 Prostaglandin G/H synthase-2 is a major contributor of brain prostaglandins in the newborn. J Biol Chem 270:24615-24620

33. Parfenova H. Levine V. Gunther WM. Pourcyrous M. Leffler CW 2002 COX-1 and COX-2 contributions to basal and IL-1 beta-stimulated prostanoid synthesis inhuman neonatal cerebral microvascular endothelial cells. Pediatr Res 52:342-348

34. Davidge ST, Baker PN, McLaughlin MK, Roberts JM 1995 Nitric oxide produced by endothelial cells increases production of eicosanoids through activation of prostaglandin H synthase. Circ Res 77:274-283

35. Schlitz JC, Sawchenko PE 2002 Distinct brain vascular cell types manifest inducible cyclooxygenase expression as a function of the strength and nature of immune insults. J Neurosci 22:5606-5618

36. Minghetti L, Walsh DT, Levi G, Perry VH1999 In vivo expression of cycoloxygenase- 2 in rat brain following intraparynchymal injection of bacterial endotoxin and inflammatory cytokines. J Neurpathol Exp Neurol 58:1184-1191
37. Gilles FH, Murphy SF 1969 Perinatal telencephalic leucoencephalopathy. J Neurol Neurosurg Psychiatry 32:404-413

38. Gilles FH, Averill DR, Kerr CS 1977 Neonatal endotoxin encephalopathy. Ann Neurol 2:49-56

39. Skultetyova I, Tokarev D, Jezova D 1998 Stress-induced increase in blood-brain barrier permeability in control and monosodium glutamate-treated rats. Brain Res Bull 45:175-178

40. Dziegielewska KM, Knott GW, Saunders NR 2000 The nature and development of the internal environment of the developing brain. Cell Mol Neurobiol 20:4156

41. Tabernero A, Granda B, Medina A, Sanchez-Abarca LI, Lavado E, Medina M 2002 Albumin promotes neuronal survival by increasing the synthesis and release of glutamate. J Neurochem 81:881-891

42. Stoll G, Jander S 1999 The role of microglia and macrophages in the pathophysiology of the CNS. Prog Neurobiol 58:233-247

43. Dammann O, Durum S, Leviton A 2001 Do white cells matter in white matter damage? Trends Neurosci 24:320-324

44. Manuelpillai U, Nicholls T, Wallace EM, Phillips DJ, Guillemin G, Walker D 2003 Increased mRNA expression of kynurenine pathway enzymes in human placentae exposed to bacterial endotoxin. Adv Exp Med Biol 527:85-89 